\title{
Panel Stiffener Debonding Analysis Using a Shell/3D Modeling Technique
}

\author{
Ronald Krueger*, James G. Ratcliffe*, Pierre J.Minguet** \\ *National Institute of Aerospace, **The Boeing Company
}

\begin{abstract}
A shear loaded, stringer reinforced composite panel is analyzed to evaluate the fidelity of computational fracture mechanics analyses of complex structures. Shear loading causes the panel to buckle. The resulting out-of-plane deformations initiate skin/stringer separation at the location of an embedded defect. The panel and surrounding load fixture were modeled with shell elements. A small section of the stringer foot, web and noodle as well as the panel skin near the delamination front were modeled with a local 3D solid model. Across the width of the stringer foot, the mixed-mode strain energy release rates were calculated using the virtual crack closure technique. A failure index was calculated by correlating the results with a mixed-mode failure criterion of the graphite/epoxy material. The objective was to study the effect of the fidelity of the local 3D finite element model on the computed mixed-mode strain energy release rates and the failure index.
\end{abstract}

Keywords: A: Structural composites; B: Delamination, C: Finite element analysis (FEA), C: Buckling; Computational fracture mechanics.

\section{Introduction}

Many composite components in aerospace structures are made of flat or curved panels with co-cured or adhesively bonded frames and stiffeners. Recent studies focused on the investigation of the debonding mechanism and included testing of skin/stiffener panels and failure analysis using shell models [1, 2]. Over the last decade, a consistent step-wise approach has been developed which uses experiments to determine the failure mechanism, 
computational stress analysis to determine the location of first matrix cracking and computational fracture mechanics to investigate the potential for delamination growth. Testing of thin-skin stiffened panels designed for use in pressurized aircraft fuselages has shown that bond failure at the tip of the frame flange is an important and very likely failure mode [3]. Comparatively simple, laboratory size coupon type specimens consisting of a stringer flange bonded onto a skin have been developed to study the fundamental mechanisms of skin/stiffener debonding [4]. The failure that initiates at the tip of the flange in these coupon type specimens is nearly identical to the failure observed in the full-scale panels and frame pull-off specimens [4-6]. A methodology based on fracture mechanics [7] has been used successfully to investigate the onset and growth of delaminations in simple characterization specimens and laboratory size coupon type specimens [5, 6]. Future acceptance of the methodology by industry and certification authorities, however, requires the successful demonstration of the methodology on a structural level.

For the demonstration of the methodology on the structural level, a stringer stiffened panel, as shown in Fig. 1, had been analyzed previously [8,9]. The square (1016 mm x $1016 \mathrm{~mm})$ panel made of carbon/epoxy tape is reinforced with three stringers made of carbon/epoxy plain weave fabric. Details will be discussed in the following sections. During manufacturing, an artificial defect of about $82 \mathrm{~mm}$ in length was placed at the termination of the center stiffener. The stiffened panel was bolted to a steel picture frame and subjected to shear loading which caused the panel to buckle as shown in the finite element model depicted in Fig. $1[8,9]$. The resulting out-of-plane deformation caused skin/stringer separation to initiate at the location of the artificial defect. A small section of the stringer foot and the panel skin in the vicinity of the embedded defect were modeled with a local 3D solid model as shown in the enlargement in Fig. 1. The mixed-mode strain energy release rates were calculated using the virtual crack closure technique $[10,11]$ across the width of the stringer foot. A failure index was calculated by correlating the results with the mixed-mode failure criterion of the graphite/epoxy material $[8,9]$.

The objective of the current research was to study the effect of the fidelity of the local 3D finite element model on the computed mixed-mode strain energy release rates and the 
failure index. In the original model, shell elements represented the skin and stiffener foot $[8,9]$. In previous studies, a model was introduced where only the stiffener foot and skin were included in a local 3D model, while the web and hat were modeled with shell elements as shown in Fig. 1. The pair of 2D illustrations in Fig. 2 are cross sections of the local 3D finite element model [8,9]. For the current study, a new set of models was introduced, as shown in Fig. 3, where the stringer web was included in the local solid model. Another set of models included the transition radius between the web and foot as well as the detailed noodle region in the local solid model as shown in Fig. 4. Details of the models are discussed later. Thus, this study considers the effects of various geometrical simplifications that might be considered by an analyst when modeling debonding in complex structures. The work discussed herein is intended to be used as a guide to determine the trade off between modeling complexity and fidelity on the corresponding results. The current research complements previous studies $[8,9]$.

\section{Methodology}

\subsection{Linear Elastic Fracture Mechanics}

Linear elastic fracture mechanics has proven useful for characterizing the onset and growth of delamination in composite laminates [7]. When using fracture mechanics, the total strain energy release rate, $G_{T}$, is calculated along the delamination front. The term, $G_{T}$, consists of three individual components. The first component, $G_{I}$, arises due to interlaminar tension. The second component, $G_{I I}$, arises due to interlaminar sliding shear (shear stresses parallel to the plane of delamination and perpendicular to the delamination front). The third component, $G_{I I I}$, arises due to interlaminar scissoring shear (shear stresses parallel to the plane of delamination and parallel to the delamination front). The calculated $G_{I}, G_{I I}$, and $G_{I I I}$ components are then compared to interlaminar fracture toughness values in order to predict delamination onset or growth. The interlaminar fracture toughness values are determined experimentally over a range of mode mixity from pure mode I loading to pure mode II loading [12-14]. 
A quasi static mixed-mode fracture criterion is determined by plotting the interlaminar fracture toughness, $G_{c}$, versus the mixed-mode ratio, $G_{I I} / G_{T}$. The fracture criteria is generated experimentally using pure Mode I $\left(G_{I I} / G_{T}=0\right)$ Double Cantilever Beam (DCB) tests, pure Mode II $\left(G_{I I} / G_{T}=1\right)$ four point End-Notched Flexure (4ENF) tests, and MixedMode Bending (MMB) tests of varying ratios of $G_{I}$ and $G_{I I}$. A fracture criterion was suggested by Benzeggah and Kenane [15] using a simple mathematical relationship between $G_{c}$ and $G_{I I} / G_{T}$ $G_{c}=G_{I c}+\left(G_{I c}-G_{I c}\right) \cdot\left(\frac{G_{I I}}{G_{T}}\right)^{\eta}$ as shown in Fig. 5.

In this expression, $G_{I c}$ and $G_{I I c}$ are the experimentally-determined fracture toughness data for mode $\mathrm{I}$ and $\mathrm{II}$. The factor $\boldsymbol{\eta}$ is determined by a curve fit. Fracture initiation is expected when, for a given mixed-mode ratio $G_{I I} / G_{T}$, the calculated total energy release rate, $G_{T}$, exceeds the interlaminar fracture toughness, $G_{c}$.

Although several specimens, including the edge-cracked torsion specimen (ECT), have been suggested for the measurement of the mode III interlaminar fracture toughness property $[16,17]$, an interaction criterion incorporating the mode III shear, however, has not yet been established. Therefore, a modified definition is introduced for threedimensional analysis, which also yields results for the scissoring mode $G_{I I I}$. In the modified definition, $G_{S}$ denotes the sum of the in-plane shearing components $G_{I I}+G_{I I}[8,9]$. This is necessary since a mixed-mode failure criterion, which accounts for all three modes, is currently not available. For analyses where $G_{I I I}=0$, this definition is equal to the commonly used definition of the mixed-mode ratio, $G_{I I} / G_{T}$ mentioned above.

To determine failure along the delamination front, the critical energy release rate, $G_{c}$, is calculated using Eq. (1) with $G_{I I}=G_{S}$ at each point along the delamination front. Subsequently, the failure index $G_{T} / G_{c}$ is determined from the computed total energy release rate, $G_{T}$, and the critical energy release rate, $G_{c}$, with the assumption that delamination propagation occurs for 


$$
\frac{G_{T}}{G_{c}} \geq 1
$$

\subsection{Analysis Tools}

\subsubsection{Virtual Crack Closure Technique}

A variety of methods are used in the literature to compute the strain energy release rate based on results obtained from finite element analysis. For delaminations in laminated composite materials where the failure criterion is highly dependent on the mixed-mode ratio, the virtual crack closure technique (VCCT) $[10,11]$ has been most widely used for computing energy release rates. VCCT calculations using continuum (2D) and solid (3D) finite element analyses provide the mode separation required when using the mixed-mode fracture criterion.

\subsubsection{A Global/Local Shell 3D Modeling Technique}

Built-up structures are traditionally modeled and analyzed using plate or shell finite elements, as shown in Fig. 1, to keep the modeling and computational effort affordable. The fidelity of the resulting computed mixed-mode strain energy release rate components, however, depends on many variables. These variables include element type, order of the shape functions and shear deformation assumptions, kinematic constraints in the neighborhood of the delamination front, and continuity of material properties and section stiffnesses in the vicinity of the debond when delaminations or debonds are modeled with plate or shell finite elements [18]. These problems may be avoided by using threedimensional models. However, since many layers of brick elements through the thickness are often necessary to model the individual plies, the size of finite element models required for accurate analyses may become prohibitively large.

For detailed modeling and analysis of the delaminations, the shell/3D modeling technique will reduce the modeling time compared to that required to run a fully three-dimensional finite element model. The technique will also reduce computational time because only a relatively small section of the mesh needs to be modeled with solid elements, minimizing 
the overall size of the model. The technique combines the accuracy of the full threedimensional solution with the computational efficiency of a plate or shell finite element model. The technique has been demonstrated for various applications such as fracture toughness characterization specimens [19], on the coupon level for the skin/stringer separation specimen [20] and in related studies for skin/stringer separation $[8,9]$. The enlargement in Fig. 1 illustrates the regions within the stringer stiffened panel that are modeled with shells and solid elements.

\section{Finite Element Modeling}

In the current study, a finite element analysis of the three-stringer panel shown in Fig. 1 was conducted. The load frame and the three-stringer panel were modeled with beam and shell elements. A small section of the stringer and the panel skin in the vicinity of the embedded defect was modeled with a local 3D model. For all analyses, the stiffener hat was modeled with shell elements. For all analyses, the finite element software ABAQUS ${ }^{\circledR}$ was used which is manufactured by Dassault Systèmes Simulia Corp. (DSS), Providence, RI, USA.

\subsection{Global Shell Model of Stringer Stiffened Panel}

The global model included the steel load frame and attachments, the panel made of graphite/epoxy prepreg tape, and the stringers made of graphite/epoxy fabric, as shown in

Fig. 1. The outer steel load frame and the attachment bolts were modeled with beam elements (ABAQUS ${ }^{\circledR}$ element type B21) [21]. The inner steel load frame, which overlaps the panel edge, was modeled with shell elements (ABAQUS ${ }^{\circledR}$ element type S4). The stiffener components, such as the foot, web and hat were also modeled with shell elements.

The panel skin and the stiffener foot are modeled as separate entities. The S4 shell elements are located at the panel skin and stiffener foot respective mid-planes. The shell elements are connected by beam elements (ABAQUS ${ }^{\circledR}$ element type B31 modeled as steel) to provide point-to-point constraints between the two surfaces [22]. In the section containing the artificial defect, the beam elements were replaced by gap elements 
(ABAQUS ${ }^{\circledast}$ element type GAPUNI). The gap elements allow the modeling of contact between two nodes. The nodes can be in contact (gap closed), which prevents element interpenetration or separated (gap open) which allows the skin/stringer separation [21].

\subsection{Local 3D Model of the Stringer Foot and Panel Skin}

The local 3D model of the stringer foot and panel skin was generated using brick elements (ABAQUS ${ }^{\oplus}$ element type C3D8I) and consisted of an intact section and a delaminated section with a fine mesh around the delamination front. Two examples with different mesh refinement (designated BF-8/10/8 and BF-20/20/20) are shown in Fig. 2. The artificial defect is located at the bondline between the stringer foot and the panel as shown in the enlargements of Fig. 2. This defect was treated as a delamination and modeled as a discrete discontinuity using two unconnected nodes with identical coordinates on each side of the delamination. Contact was modeled between the delaminated surfaces to avoid interpenetration during the analysis.

Four elements through the thickness were used to model the foot of the stiffener made of carbon/epoxy fabric as shown in the 2D cross sections in Fig. 2. The skin ply made from carbon/epoxy tape which is adjacent to the plane of the delamination was modeled with one element through the thickness. The remaining 10 plies of carbon/epoxy tape were modeled with three elements through the thickness as shown in Fig. 2.

\subsection{Local 3D Model of the Panel Skin, Stringer Foot and Web}

The modeling fidelity was increased by including the stiffener web in the local 3D model as shown in Fig. 3 (TFL3-8/10/8, TFL3-20/20/20). The local 3D model shown consisted of two separately meshed sections: the stiffener web and the panel skin/stiffener foot. The web was modeled with eight brick elements (ABAQUS ${ }^{\boxplus}$ element type C3D8I) through the thickness. The two models are connected to each other using multipoint constraints (ABAQUS ${ }^{\boxplus}$ MPC option *TIE). The multipoint constraints are used to tie two surfaces together for the duration of a simulation, which makes the translational and rotational motion equal for a pair of surfaces. Nodes on the slave surface (defined by the user) are 
constrained to have the same motion as the point on the master surface (defined by the user) to which it is closest [21].

\subsection{Local 3D Model of the Panel Skin, Stringer Foot and Web Including the Noodle and Transition Radius}

The modeling fidelity was increased further by including the noodle region and transition radius in the local 3D model as shown in Fig. 4 (TN1L3C-8/10/8, TN1L3C-20/20/20). The triangular region underneath the web, where the stiffener connects to the skin, is usually referred to as a noodle. As above, the local 3D model shown consisted of two separately meshed sections which are connected with tie constraints: The model of the stiffener including the web, noodle region and transition radius and the model of panel skin and delaminated interface is shown in the cross section of Fig. 4. The two solid models were joined using the $*$ TIE option in ABAQUS ${ }^{\circledR}$ [21]. The solid model of the stringer foot and delamination consisted of brick elements (ABAQUS ${ }^{\circledR}$ element type C3D8I) and included an intact section and a delaminated section with a fine mesh around the delamination front, as discussed above.

Solid models representing the stiffener foot, the web and the noodle region consisted of eight-node C3D8I brick elements, with a small number of six-node C3D6 prism elements used to model part of the noodle region as shown in the cross sections of Fig. 4 . Since the exact transition radius was not known, the influence of detailed local 3D modeling on computed strain energy release rates was studied. In this case, a number of models were generated with different foot/web transition radii. Four models were generated with radius values of $0.254 \mathrm{~mm}$, and $0.711 \mathrm{~mm}, 2.54 \mathrm{~mm}$ and $5.08 \mathrm{~mm}$. Models with radii $2.54 \mathrm{~mm}$ and $0.711 \mathrm{~mm}$ were thought to correspond to values used in manufactured panels. The small radius $0.254 \mathrm{~mm}$ (cross section shown in Fig. 4c) was selected to determine if the computed results were similar to those obtained from the model discussed in section 3.3 which did not included the radius and noodle. The larger radius $5.08 \mathrm{~mm}$ (cross section shown in Fig. 4c) was chosen as an upper limit. It did not appear to be meaningful from a design standpoint to assume larger radii. 


\subsection{Finite Element Model Assembly, Load and Boundary Conditions}

The local 3D models were placed to complete the assembled model as shown in the enlargement of Fig. 1. At the boundaries, the nodes along the shell edges were used to connect the shell model with the local 3D solid models. The connection was accomplished using the shell to solid coupling option in ABAQUS ${ }^{\circledR}$, which allows the connection between non-conforming shell and solid models. The coupling option uses a set of internally defined distributing coupling constraints to couple the motion of a row of nodes along the edge of the shell model to the motion of a set of nodes defined on a surface of the solid model [21].

For modeling the experiment, which was performed under displacement control, uniform displacements $u, v$ were applied at one corner node to introduce shear as shown in Fig. 1. The in-plane displacements, $u, v$, were suppressed at the diagonally opposite corner and the out-of-plane displacements, $w$, were suppressed along all four edges across the entire width of the inner and outer steel load frame.

\subsection{Analysis Overview}

A total of 41 different model combinations were analyzed. An overview of all models generated is given in reference [23]. The following cases are discussed here:

- Models were analyzed where only the stiffener foot and skin were included in a local 3D model, while the web and hat were modeled with shell elements as shown in Fig. 2.

- A set of models were created, as shown in Fig. 3, where the stringer web was included in the local solid model.

- Another set of models included the transition radius between the web and foot as well as the detailed noodle region in the local solid model as shown in Fig. 4. The stiffener hat, modeled with shell elements, was kept unchanged. Four different transition radii were studied $(\mathrm{r}=0.254 \mathrm{~mm}, 0.711 \mathrm{~mm}, 2.54 \mathrm{~mm}, 5.08 \mathrm{~mm})$.

- In order to capture the local failure near the edges, models with a locally refined fine mesh were chosen as shown in the cross sections of Fig. 2 to 4 . In order to 
capture the local failure index distribution in the vicinity of the web termination, models with a fine mesh in the center were chosen (also shown in Fig. 2 to 4 ).

\section{Analysis Results}

\subsection{Model Deformation}

Under the applied shear loading, the analysis predicts the buckling deformation shown in Fig. 1. For the simulated delamination length $(a=81.9 \mathrm{~mm})$, three peaks and one trough can be observed in the panel bays adjacent to the center stiffener as shown in Fig. 1. More details may be found in a previous study [8].

Details of the deformed finite element models are shown in the enlargements of Fig. 2 to 4 after the entire external displacement $u=v=6.35 \mathrm{~mm}$ had been applied. Mode I opening was observed across the entire width of the stringer over the entire delaminated length.

\subsection{Comparison of Failure Indices Computed from Different Local 3D Models}

For each nodal point along the delamination front, the critical energy release rate, $G_{c}$, was calculated from a mixed-mode failure criterion (Eq. 1) for the computed mixed-mode ratio, $G_{S} / G_{T}$. Subsequently, the failure index $G_{T} / G_{c}$ was calculated from Eq. 2 . The failure index was calculated for the final load increment and plotted versus the location, $s$, across the width of the stringer, $b$, as shown in Fig. 1 and 2 .

The computed failure index distributions across the width of the stringer obtained from different models were plotted in Fig. 6 to 12 for comparison with reference results. The combined results from the models with refined edges and center (Fig. 2) were used as reference results in all the figures and are depicted as blue circles. For all cases shown, the failure index peaked at the edges $(s=0.0$ and $\mathrm{s}=1.0$ ) with an additional peak around the center $(s \approx 0.5)$ underneath the stringer web.

First, the results obtained from a model that included the panel skin, stiffener foot and the web in the local solid model as shown in Fig. 3 were plotted in Fig. 6 for comparison with 
the reference result. Qualitatively, both distributions followed the same trend. In two areas to the left and right of the web $(0.0 \leq s \leq 0.4$ and $0.7 \leq s \leq 1.0)$, the results are in good agreement. Locally, near the web $(0.4 \leq s \leq 0.7)$, the distributions differ. The peak values computed for the local solid model that included the web (red squares) exceed the reference values (blue circles) by about $49 \%$. The peak location is also offset.

The results obtained for a transition radius $r=0.711 \mathrm{~mm}$ are plotted in Fig. 7 . In the area to the left of the web $(0.0 \leq s \leq 0.4)$, the results are in good agreement. In the areas to the right of the web $(0.7 \leq s \leq 1.0)$, the results are higher for the models which included the web and the noodle (green diamonds). An additional small plateau was observed for $0.47<s<0.49$ $\left(G_{T} / G_{c} \approx 29\right)$ which was not observed in the results used as reference. Also, the peak values computed for the local solid model that included the web and the noodle exceed the reference values (blue circles) by about $67 \%$. As before, the peak location is offset compared to the reference results.

For the results computed for the larger transition radius $(r=2.54 \mathrm{~mm})$, an additional local maximum was observed for $0.44<s<0.46\left(G_{T} / G_{c} \approx 15\right)$ as shown in Fig. 8. In the areas to the right of the web $(0.7 \leq s \leq 1.0)$, the results are higher for the models, which included the web and the noodle (orange triangles). Also, the peak values computed for the local solid model that included the web and the noodle exceed the reference values (blue circles) by about $51 \%$. For this transition radius, the peak location is almost identical to the peak observed for the reference results.

The results obtained for a smaller transition radius ( $r=0.254 \mathrm{~mm}$ as shown in Fig. $4 \mathrm{c})$ are plotted in Fig. 9. In two areas to the left and right of the web $(0.0 \leq s \leq 0.4$ and $0.7 \leq s \leq$ $1.0)$, the results are in good agreement. Locally, near the web $(0.4 \leq s \leq 0.7)$ the distributions differ. The peak values computed for the local solid model that included the web and noodle (black triangles) exceed the reference values (blue circles) by about $51 \%$. The peak location is also offset. 
The results computed for a larger transition radius ( $r=5.08 \mathrm{~mm}$ as shown in Fig. $4 \mathrm{c}$ ) are plotted in Fig. 10. In the area to the left of the web $(0.0 \leq s \leq 0.4)$, the results are in good agreement. For the local solid model that included the web and noodle (black triangles), an additional local maximum was observed for $s \approx 0.4\left(G_{T} / G_{c} 5\right)$ which was not observed in the results used as reference (blue circles). In the areas right of the web $(0.7 \leq s \leq 1.0)$, the results are higher for the models which included the web and the noodle. For this transition radius, the peak value is almost identical to the peak failure index computed for the reference results.

For closer comparison, the computed failure index distributions across the width of the stringer are plotted in Fig. 11 and 12 for all models discussed. In the area to the left of the web $(0.0 \leq s \leq 0.4)$, the failure index is low and all results are generally in good agreement. The peak values computed for the local solid models that included the web and the models that included the web and the noodle exceed the reference values (blue circles), which were obtained from models where the web had been modeled with shell elements. The location where the peak failure index was observed shifted from model to model. The results obtained from models where only the web was included in the local solid model (red squares) were in excellent agreement with the failure indices computed from the model with the smallest radius ( $r=0.254 \mathrm{~mm}$, black triangles) and, therefore the smallest noodle region (Fig. 11). In two areas to the left and right of the web $(0.0 \leq s \leq 0.4$ and $0.7 \leq$ $s \leq 1.0$ ), the results are in good agreement with the reference results. Locally, near the web $(0.4 \leq s \leq 0.7)$, the distributions differ up to $67 \%$ as discussed above. For models with larger radii ( $r=0.711 \mathrm{~mm}$, green diamonds; $r=2.54 \mathrm{~mm}$, orange triangles and $r=5.08 \mathrm{~mm}$, red squares), an additional local maxima or plateau was observed for $0.4<s<0.5$ as shown in Fig. 12. With increasing radius, the peak value decreases and shifts to the right of the center $0.5<s<0.6$. Also, in the area to the right of the web $(0.7 \leq s \leq 1.0)$, the results are lower for the models with larger transition radius. 


\section{Summary and Concluding Remarks}

The skin/stringer separation of a graphite/epoxy composite panel reinforced with three stringers and subjected to shear loading was studied using computational fracture mechanics analysis. The shear loading causes the panel to buckle and the resulting out-ofplane deformation initiates skin/stringer separation at the location of an embedded defect. The panel and surrounding load fixture were modeled with shell elements.

A small section of the stringer foot, web and noodle as well as the panel skin in the vicinity of the delamination front were modeled locally with 3D solid elements. The mixed-mode strain energy release rates were calculated along a straight delamination front across the width of the stringer foot using the virtual crack closure technique. A failure index was calculated by correlating the results with a mixed-mode failure criterion of the graphite/epoxy material. Computed failure indices were compared to corresponding results where the entire web was modeled with shell elements and only a small section of the stringer foot and panel was modeled locally with solid elements.

The results showed the following

- including the stiffener web in the local 3D model increased the computed failure index by about $49 \%$ compared to the reference results where the web was modeled with shells

- including the web, the noodle and transition radius in the local 3D solid model increased the magnitude of the failure index up to $67 \%$ and changed the local distribution across the width

- the magnitude of the failure index decreased with increasing transition radius.

Differences in the failure index distributions were likely caused by a different local deformation behavior due to different local stiffnesses of the models studied. The local differences in stiffness were mainly caused by the local modeling of the noodle and the transition radius. Based on the increase in computed failure index, it is suggested to use a high fidelity model including the noodle and transition radius whenever accurate analysis results are required. The results of this study are intended to be used as a guide for conducting finite element analyses of structures such as stiffened panels. In particular, this 
guidance is aimed towards analyses that attempt to simulate delamination growth and debonding.

\section{Acknowledgements}

This work was performed at the Durability, Damage Tolerance and Reliability Branch, NASA Langley Research Center, Hampton, Virginia, USA. The research was supported by the Aircraft Aging and Durability Project as part of NASA's Aviation Safety Program.

\section{References}

[1] B.G. Falzon, G.A.O. Davies, and E. Greenhalgh, Failure of Thick-Skinned Stiffener Runout Sections Loaded in Uniaxial Compression, Composite Structures, vol. 53, pp. 223-233, 2001.

[2] J.W.H. Yap, M.L. Scott, R.S. Thomson, and D. Hachenberg, The Analysis of Skinto-Stiffener Debonding in Composite Aerospace Structures, Composite Structures, vol. 57, pp. 425-435, 2002.

[3] P.J. Minguet, M.J. Fedro, T.K. O'Brien, R.H. Martin, and L.B. Ilcewicz, Development of a Structural Test Simulating Pressure Pillowing Effects in Bonded Skin/Stringer/Frame Configuration, in Proceedings of the Fourth NASA/DoD Advanced Composite Technology Conference, Salt Lake City, Utah, 1993.

[4] P.J. Minguet and T.K. O'Brien, Analysis of Test Methods for Characterizing Skin/Stringer Debonding Failures in Reinforced Composite Panels, in Composite Materials: Testing and Design (Twelfth Volume), ASTM STP 1274, pp. 105-124, 1996.

[5] R. Krueger, M.K. Cvitkovich, T.K. O'Brien, and P.J. Minguet, Testing and Analysis of Composite Skin/Stringer Debonding Under Multi-Axial Loading, Journal of Composite Materials, vol. 34, pp. 1263-1300, 2000.

[6] R. Krueger, I.L. Paris, T.K. O'Brien, and P.J. Minguet, Fatigue Life Methodology for Bonded Composite Skin/Stringer Configurations, Journal of Composites Technology and Research, vol. 24, pp. 56-79, 2002.

[7] T.K. O'Brien, Fracture Mechanics of Composite Delamination, in ASM Handbook, Volume 21, Composites: ASM International, pp. 241-245, 2001.

[8] R. Krueger and P.J. Minguet, Skin-Stiffener Debond Prediction Based on Computational Fracture Analysis, NIA Report No. 2005-06, NASA/CR-2005213915, 2005. 
[9] R. Krueger and P.J. Minguet, Analysis of Composite Panel-Stiffener Debonding Using a Shell/3D Modeling Technique, NIA Report No. 2006-02, NASA/CR-2006214299, 2006.

[10] E.F. Rybicki and M.F. Kanninen, A Finite Element Calculation of Stress Intensity Factors by a Modified Crack Closure Integral, Eng. Fracture Mech., vol. 9, pp. 931-938, 1977.

[11] R. Krueger, Virtual Crack Closure Technique: History, Approach and Applications, Applied Mechanics Reviews, vol. 57, pp. 109-143, 2004.

[12] ASTM D 5528-94a, Standard Test Method for Mode I Interlaminar Fracture Toughness of Unidirectional Fiber-Reinforced Polymer Matrix Composites, in Annual Book of ASTM Standards, vol. 15.03, 2000.

[13] ASTM D 6671-01, Standard Test Method for Mixed-Mode I-Mode II Interlaminar Fracture Toughness of Unidirectional Fiber Reinforced Polymer Matrix Composites, in Annual Book of ASTM Standards, vol. 15.03, 2000.

[14] R.H. Martin and B.D. Davidson, Mode II Fracture Toughness Evaluation Using A Four Point Bend End Notched Flexure Test, Plastics, Rubber and Composites, vol. 28, pp. 401-406, 1999.

[15] M.L. Benzeggagh and M. Kenane, Measurement of Mixed-Mode Delamination Fracture Toughness of Unidirectional Glass/Epoxy Composites with Mixed-Mode Bending Apparatus, Composites Science and Technology, vol. 56, pp. 439-449, 1996.

[16] P. Robinson and D.Q. Song, A new Mode III Delamination Test for Composites, Advanced Composites Letters, vol. 1, pp. 160-164, 1992.

[17] J.G. Ratcliffe, Characterization of the Edge Crack Torsion (ECT) Test for Mode III Fracture Toughness Measurement of Laminated Composites, NASA/TM-2004213269, 2004.

[18] E.H. Glaessgen, W.T. Riddell, and I.S. Raju, Nodal Constraint, Shear Deformation and Continuity Effects Related to the Modeling of Debonding of Laminates, Using Plate Elements, CMES, vol. 3, pp. 103-116, 2002.

[19] R. Krueger and T.K. O'Brien, A Shell/3D Modeling Technique for the Analysis of Delaminated Composite Laminates, Composites Part A: Applied Science and Manufacturing, vol. 32, pp. 25-44, 2001.

[20] R. Krueger and P.J. Minguet, Analysis of Composite Skin-Stiffener Debond Specimens Using a Shell/3D Modeling Technique and Submodeling, NIA Report No. 2004-04, NASA/CR-2004-212684, 2004.

[21] ABAQUS 6.6, Analysis User's Manual: ABAQUS, Inc., 2005.

[22] P. Minguet, Boeing SARAP Status Report - Durability (2nd Quarter 2002), 2002.

[23] R. Krueger, J.G. Ratcliffe, and P.J. Minguet, Analysis of Composite Panel-Stiffener Debonding Using A Shell/3D Modeling Technique, NIA Report No. 2007-07, NASA/CR-2007-214879, 2007. 


\section{Figure Captions}

Figure 1. Buckling of stringer stiffened panel subjected to shear loading $(1016 \mathrm{~mm} \mathrm{x}$ $1016 \mathrm{~mm})$

Figure 2. Local 3D model of panel skin and stiffener foot

(a) Model with refined mesh near the edges (BF-8/10/8)

(b) Model with refined mesh near the center (BF-20/20/20)

Figure 3. Local 3D model of panel skin, stiffener foot and web

(a) Model with refined mesh near the center (TFL3-20/20/20)

(b) Model with refined mesh near the edges (TFL3-8/10/8)

Figure 4. Local 3D model of panel skin, stiffener foot and web including the noodle and transition radius

(a) Model with refined mesh near the edges (TN1L3C-8/10/8)

(b) Model with refined mesh near the center (TN1L3C-20/20/20)

(c) Detail of radius and noodle for models with different radii

Figure 5. Mixed-mode failure criterion

Figure 6. Computed failure index $-3 \mathrm{D}$ web results versus reference solution

Figure 7. Computed failure index - results for transition radius $r=0.711 \mathrm{~mm}$ versus reference solution

Figure 8. Computed failure index - results for transition radius $r=2.54 \mathrm{~mm}$ versus reference solution

Figure 9. Computed failure index - results for transition radius $r=0.254 \mathrm{~mm}$ versus reference solution

Figure 10. Computed failure index - results for radius $r=5.08 \mathrm{~mm}$ versus reference solution

Figure 11. Comparison of results for 3D web, radius $r=0.254 \mathrm{~mm}$ and reference solution Figure 12. Comparison of results for different radii and reference solution 


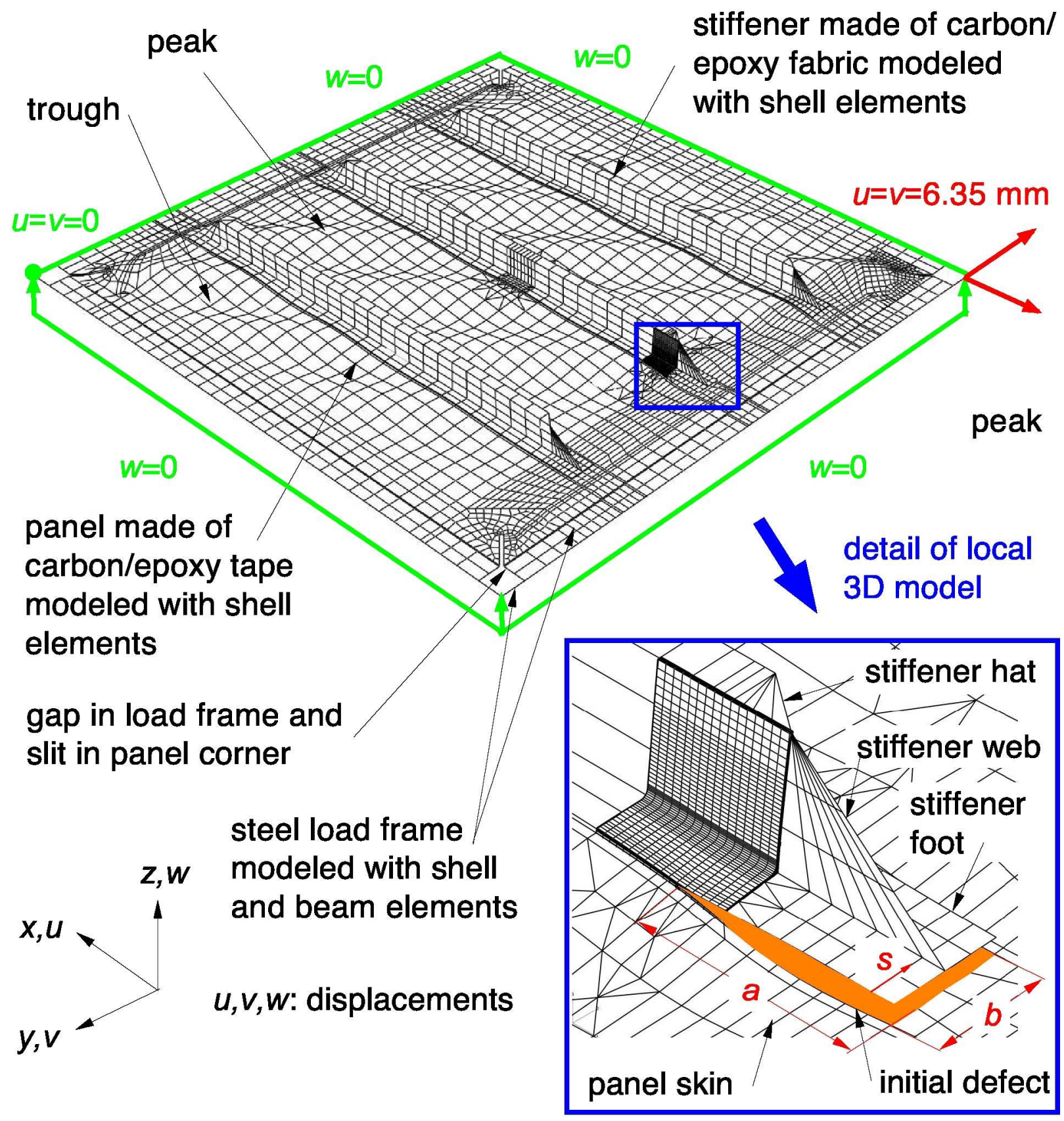

Figure 1. Buckling of stringer stiffened panel subjected to shear loading (1016 mm x $1016 \mathrm{~mm}$ ) 

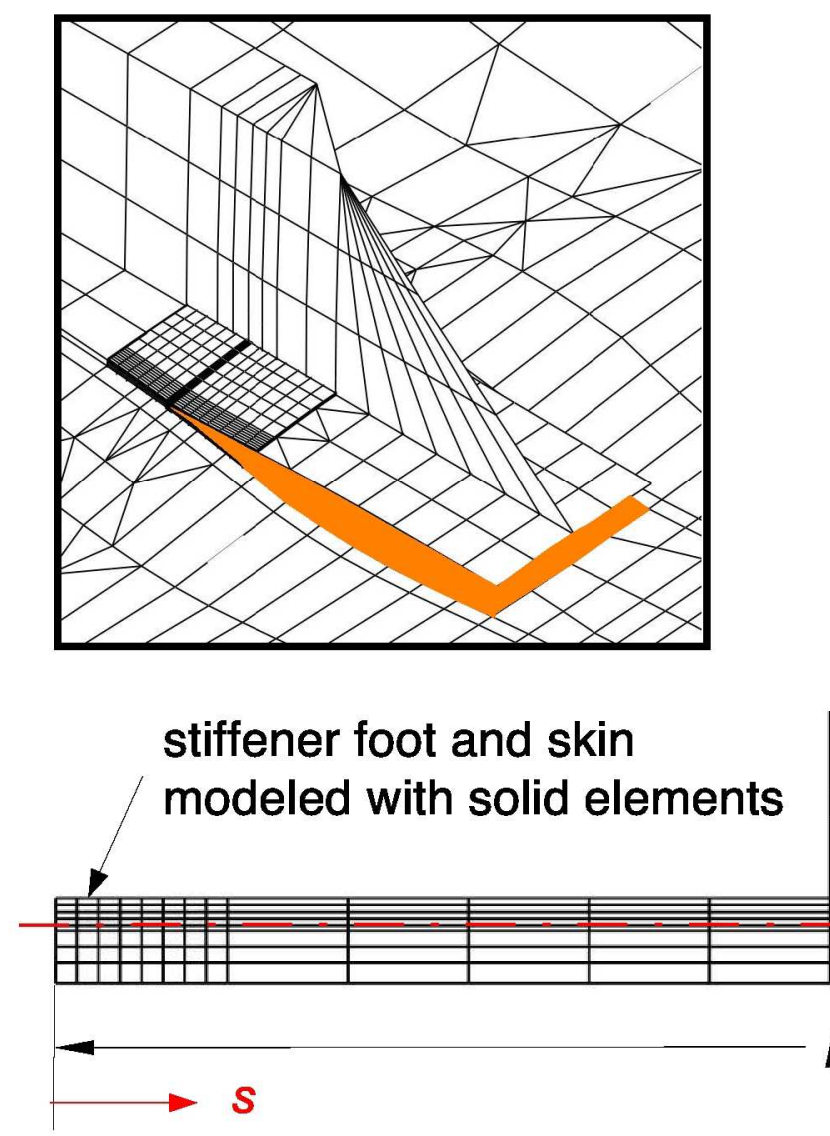

$s=0.0$ stiffener web modeled with shell elements (shell offset $=0$ )

\section{plane of} delamination

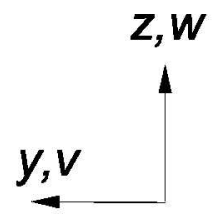

(a) Model with refined mesh near the edges (BF-8/10/8)

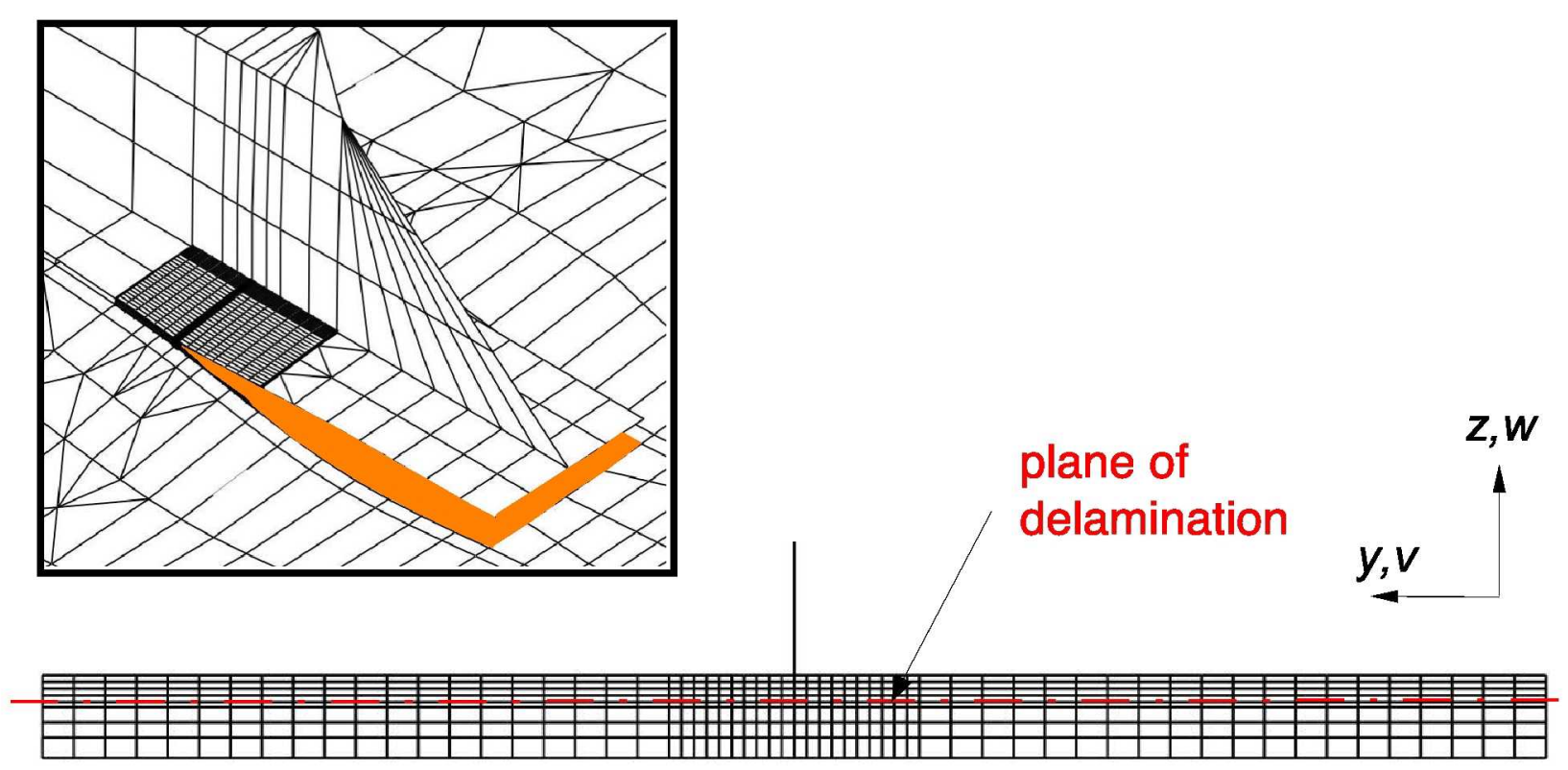

(b) Model with refined mesh near the center (BF-20/20/20)

Figure 2. Local 3D model of panel skin and stiffener foot 


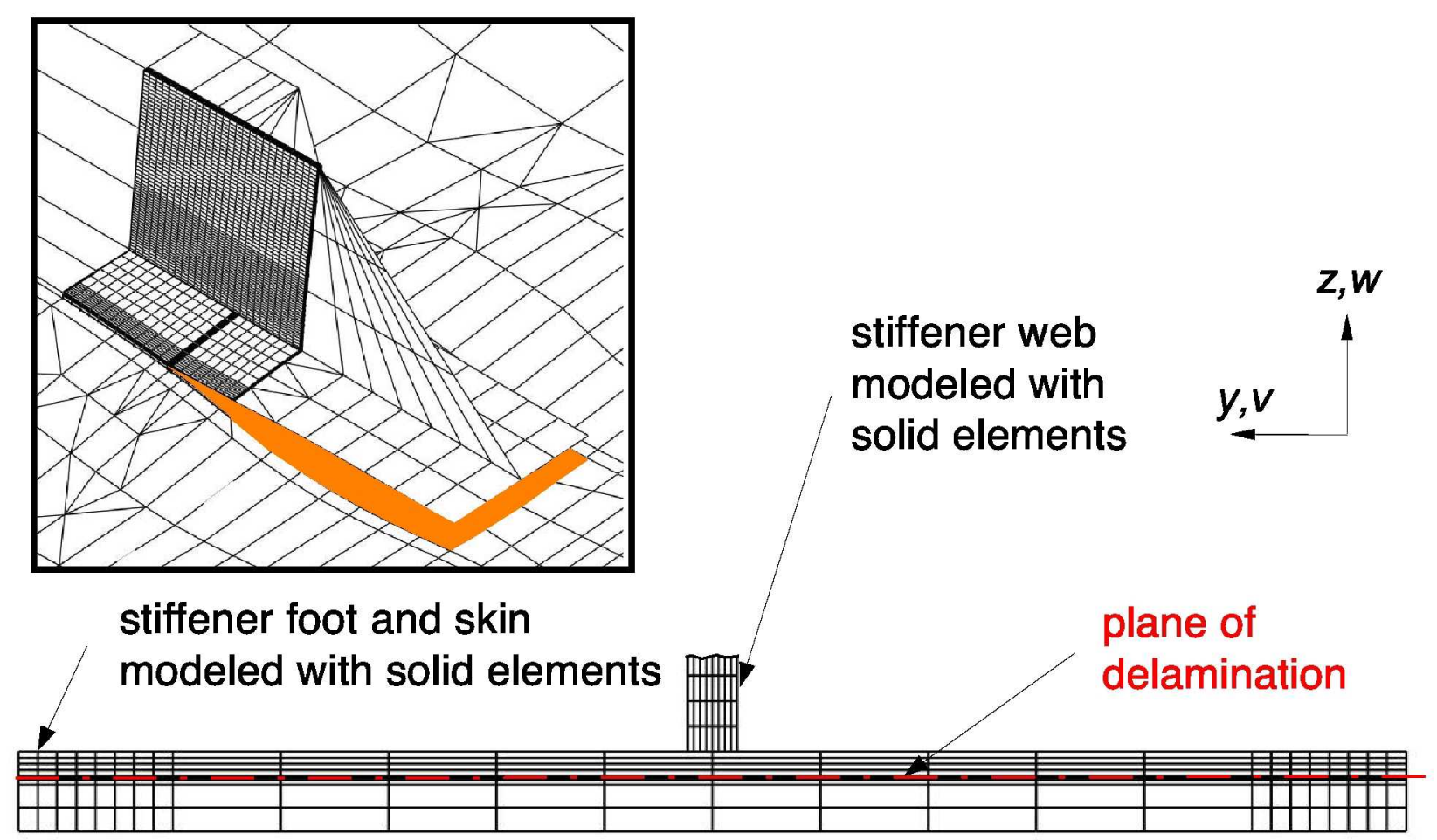

(a) Model with refined mesh near the center (TFL3-20/20/20)

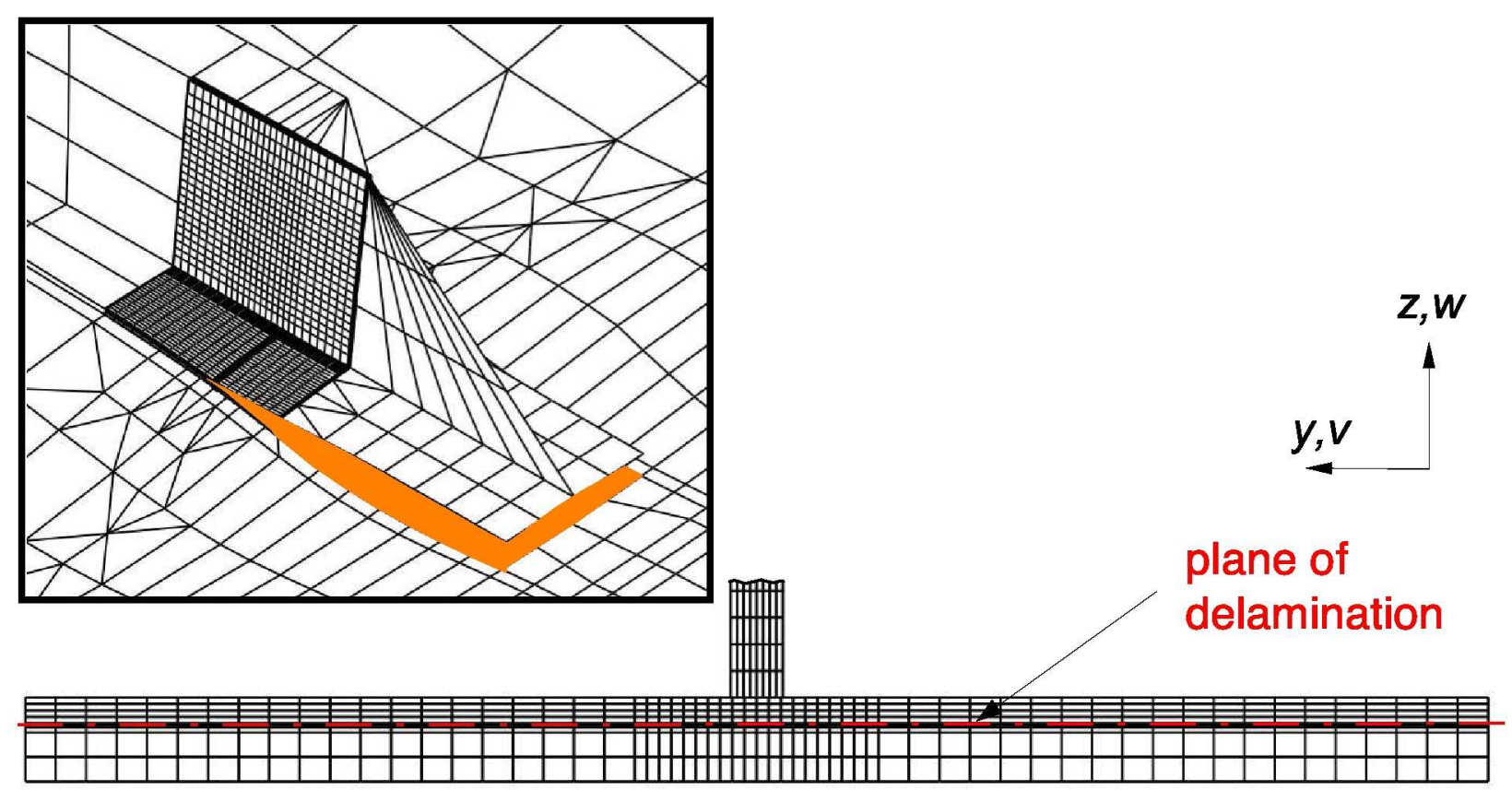

(b) Model with refined mesh near the edges (TFL3-8/10/8)

Figure 3. Local 3D model of panel skin, stiffener foot and web 


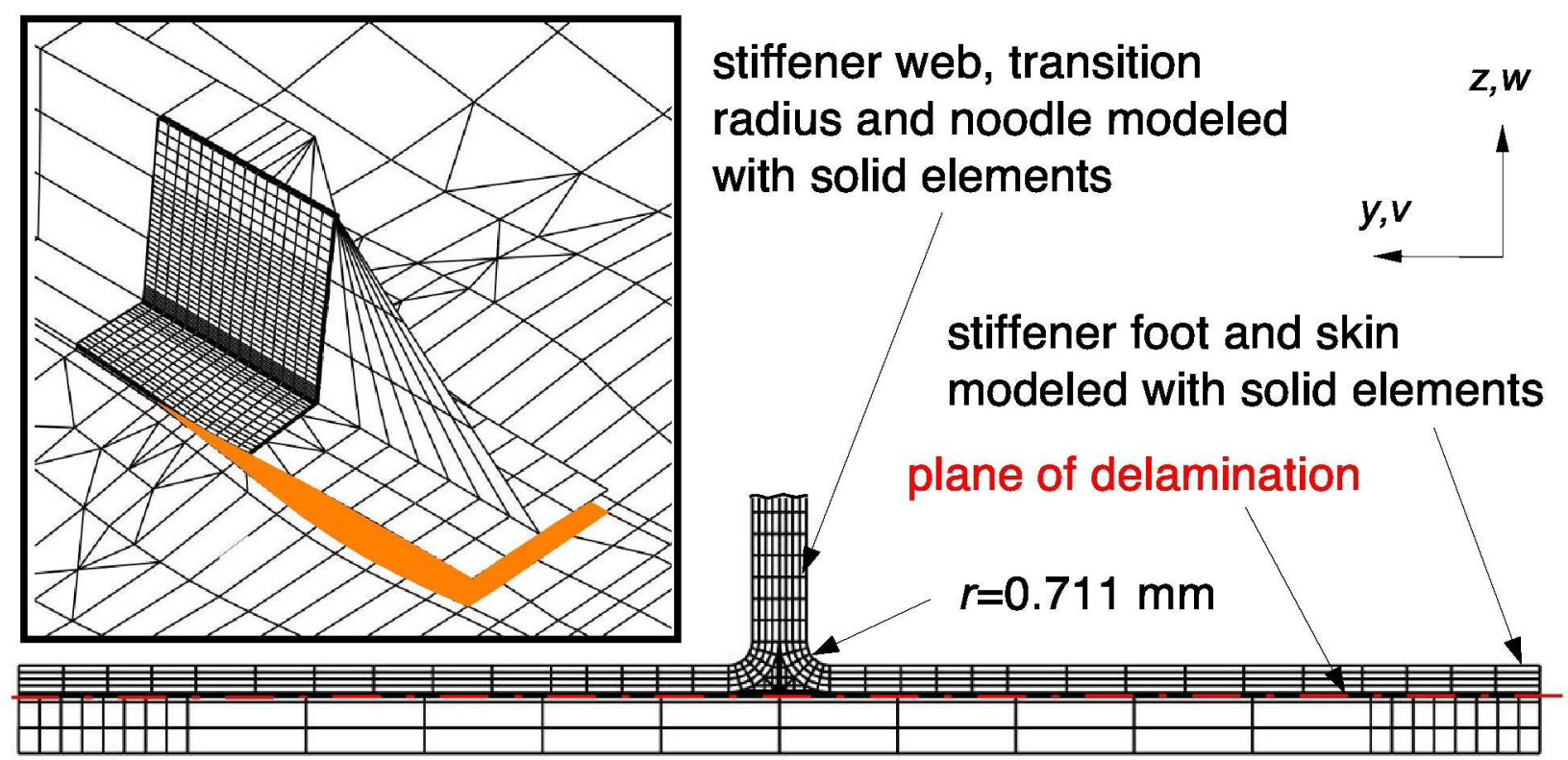

(a) Model with refined mesh near the edges (TN1L3C-8/10/8)

radii $r=0.254 \mathrm{~mm}, 0.711 \mathrm{~mm}$, $2.54 \mathrm{~mm}$, and $5.08 \mathrm{~mm}$ modeled

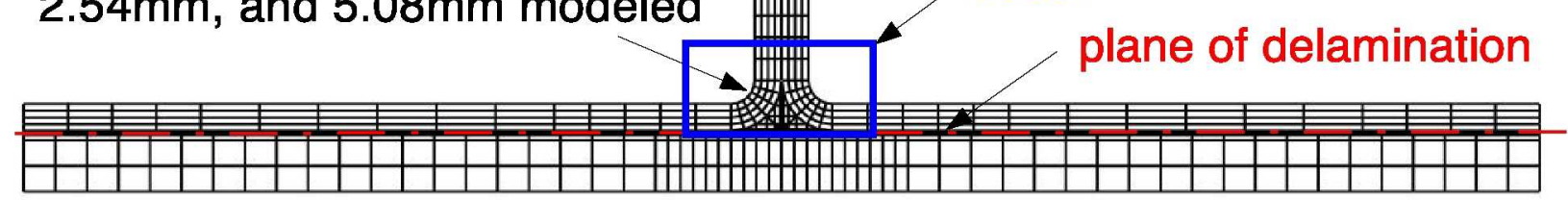

(b) Model with refined mesh near the center (TN1L3C-20/20/20)

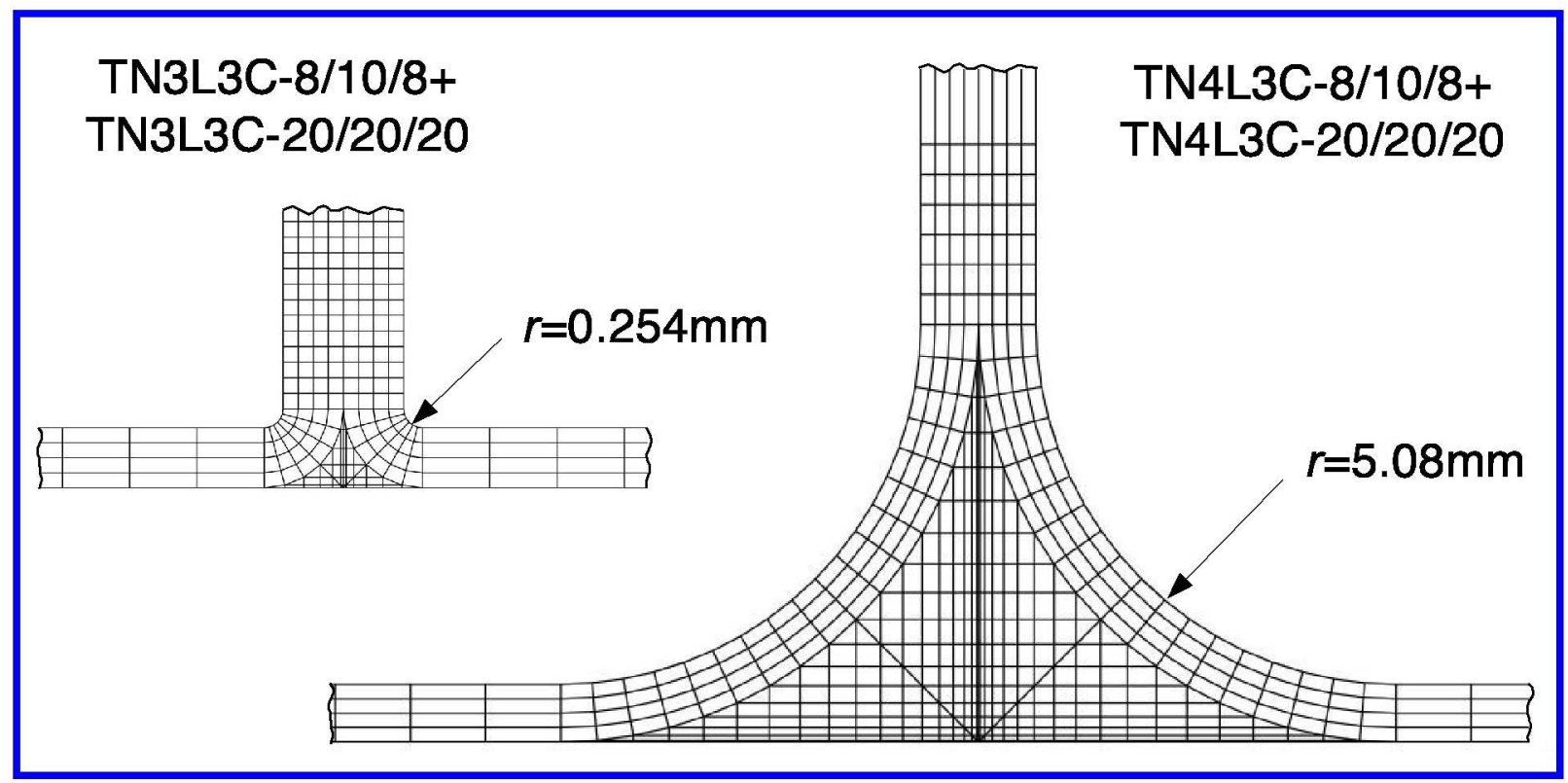

(c) Detail of radius and noodle for models with different radii

Figure 4. Local 3D model of panel skin, stiffener foot and web including the noodle and transition radius 


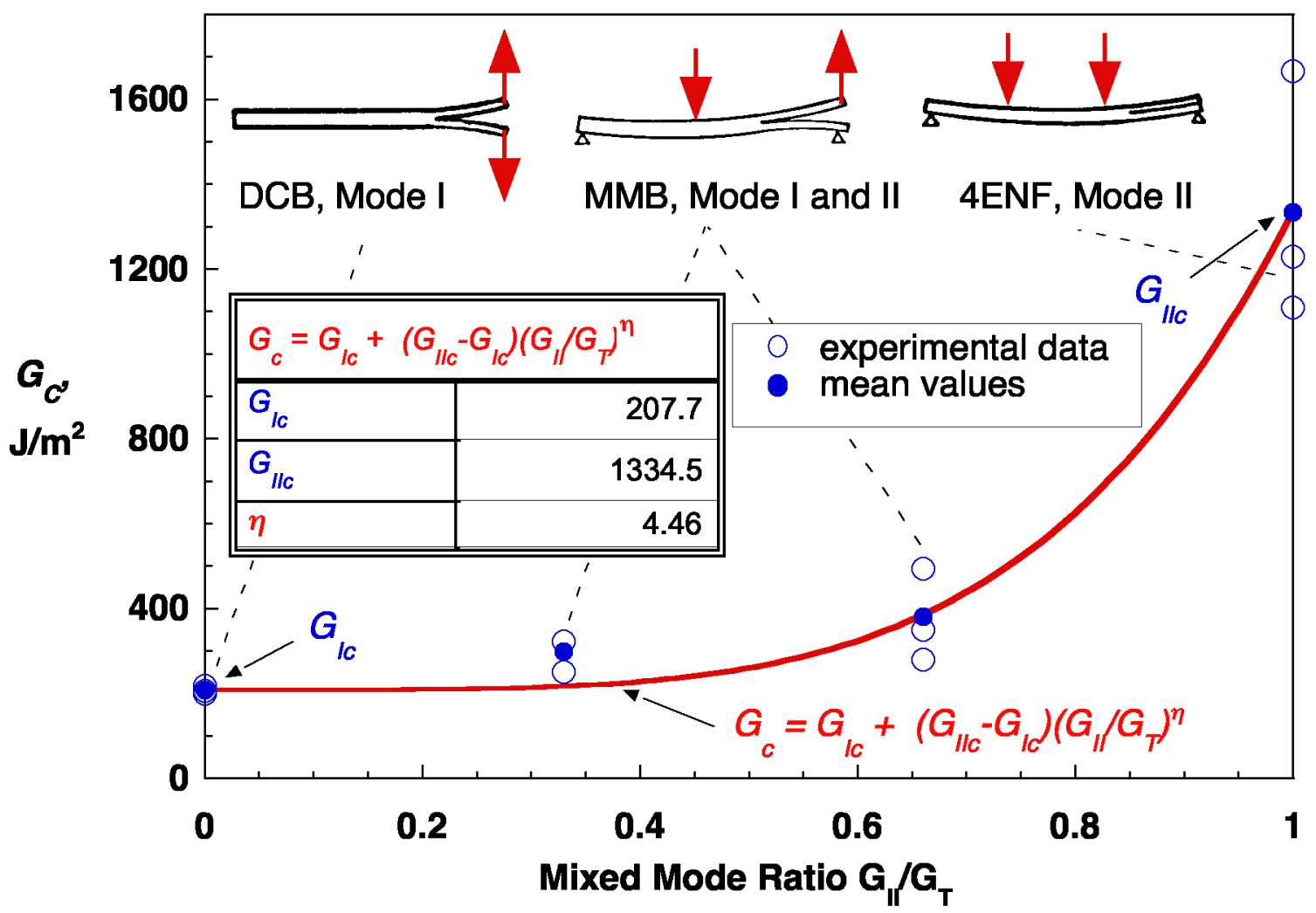

Figure 5. Mixed-mode failure criterion

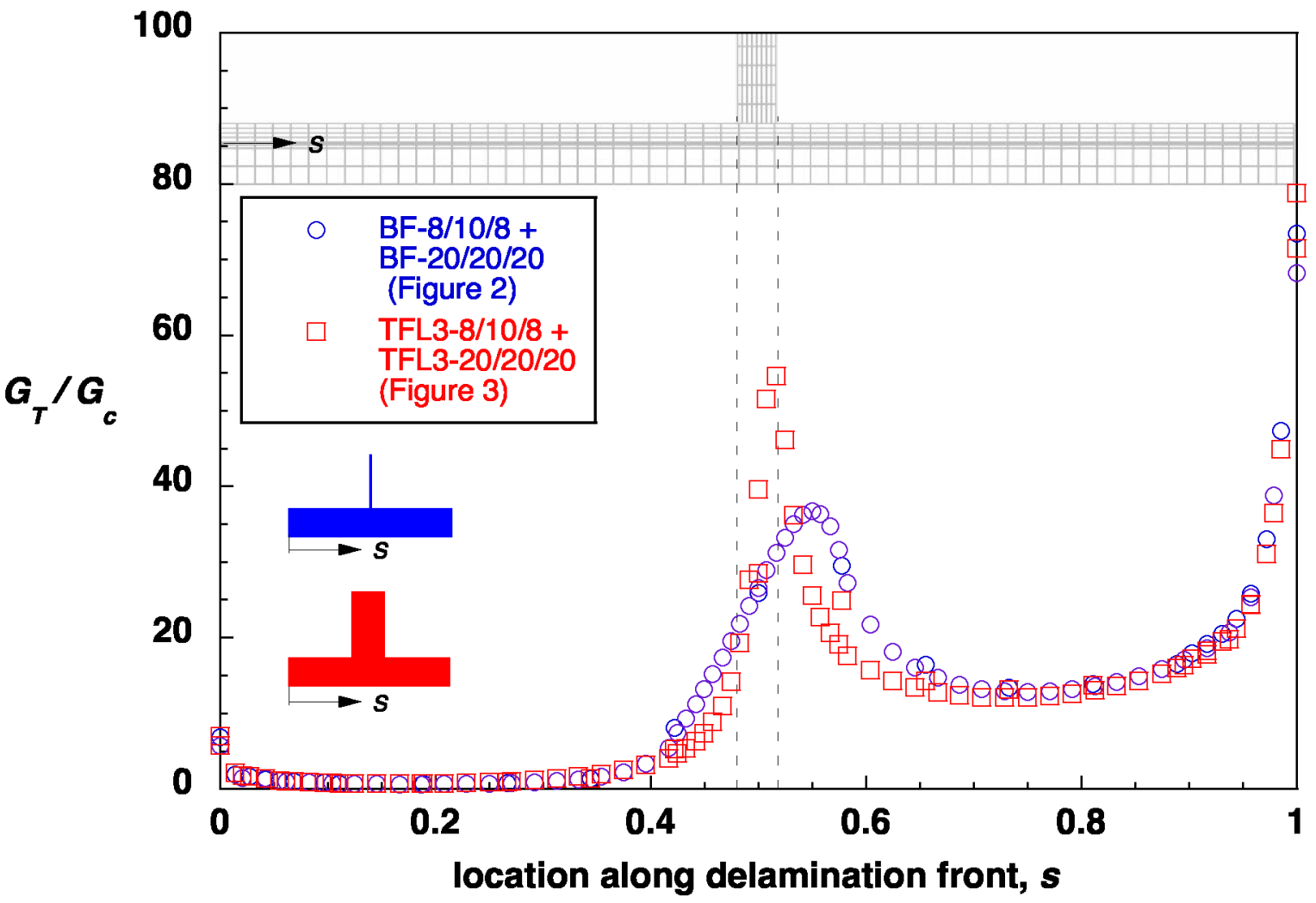

Figure 6. Computed failure index - 3D web results versus reference solution 


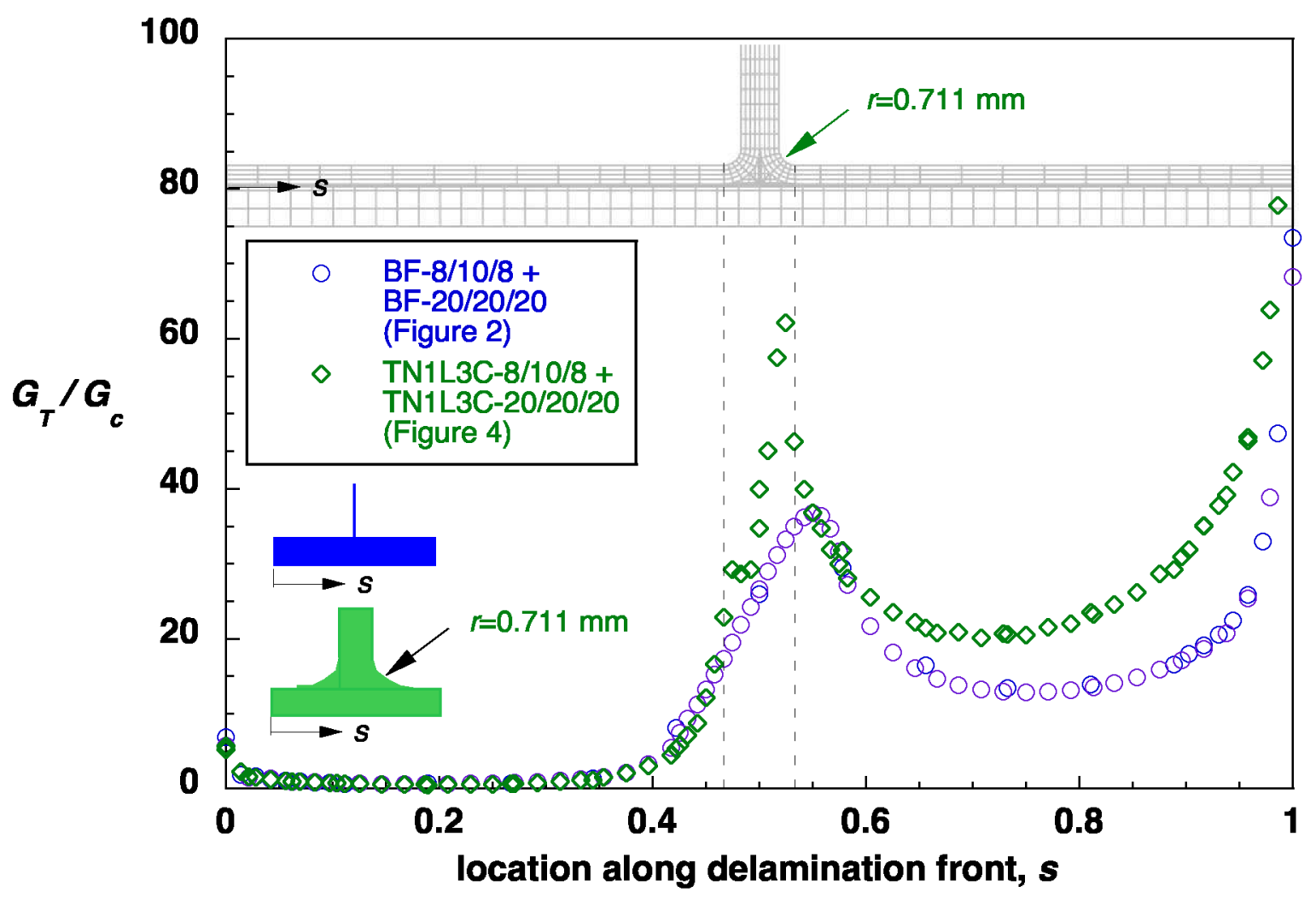

Figure 7. Computed failure index - results for transition radius $r=0.711 \mathrm{~mm}$ versus reference solution

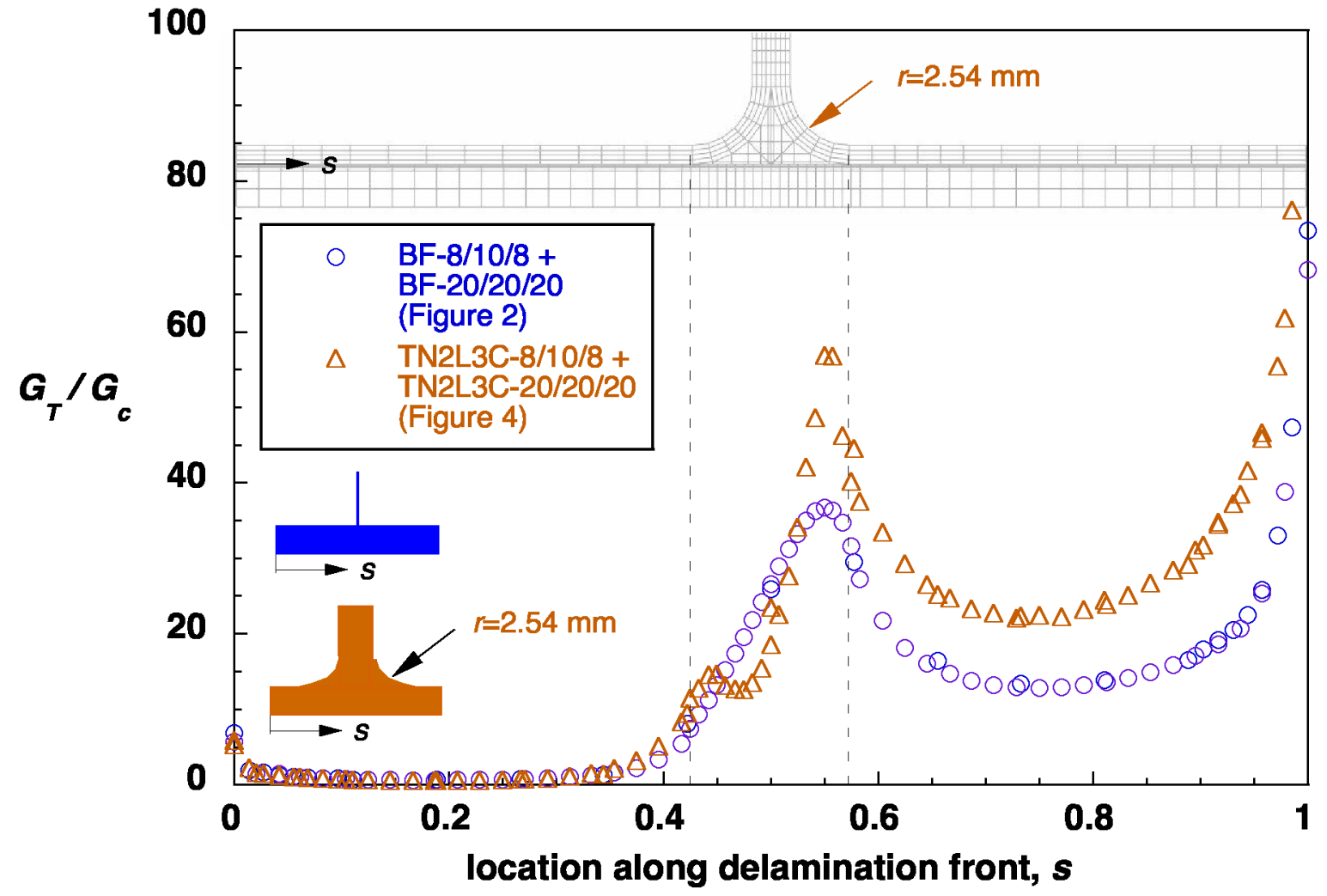

Figure 8. Computed failure index - results for transition radius $r=2.54 \mathrm{~mm}$ versus reference solution 


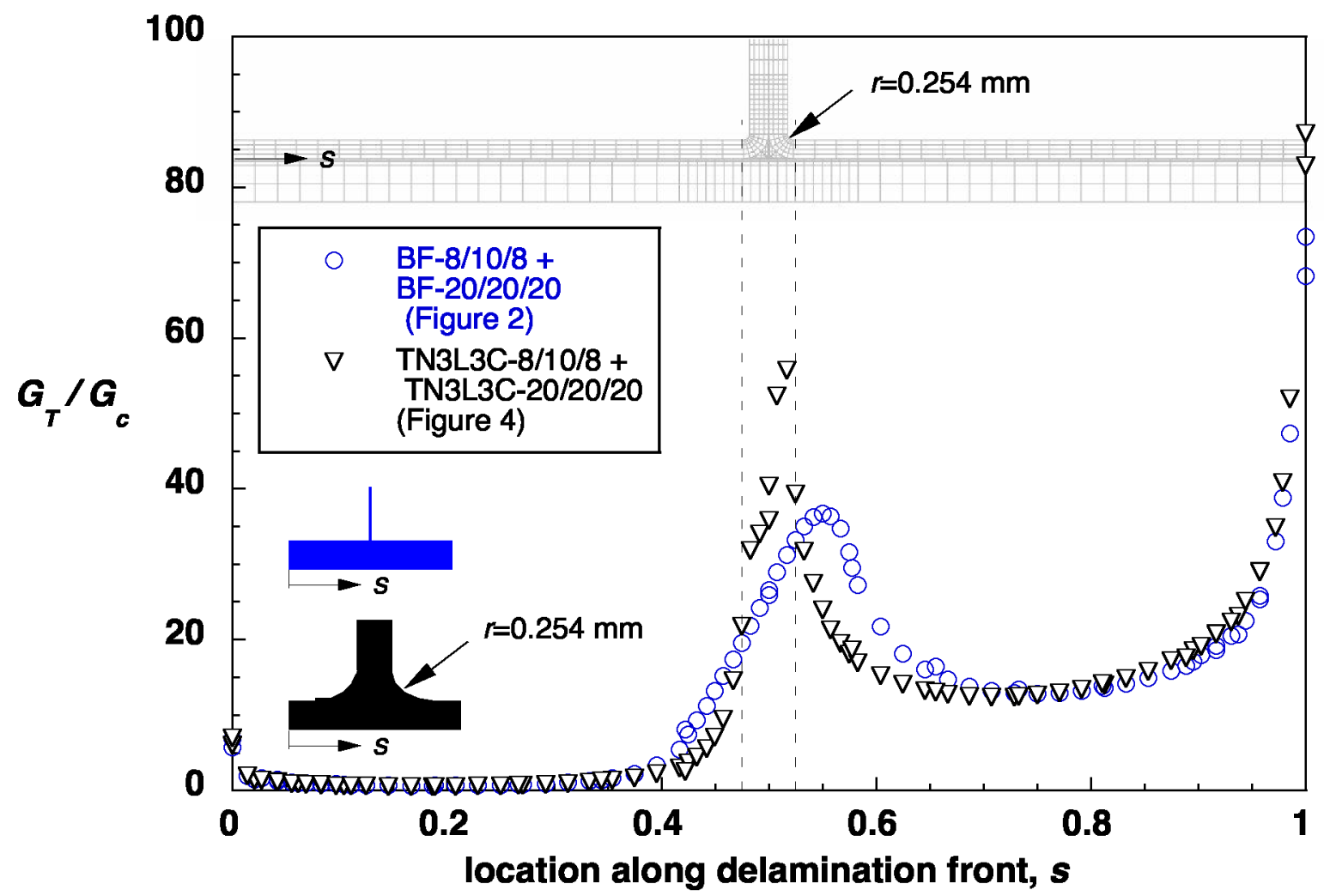

Figure 9. Computed failure index - results for transition radius $r=0.254 \mathrm{~mm}$ versus reference solution

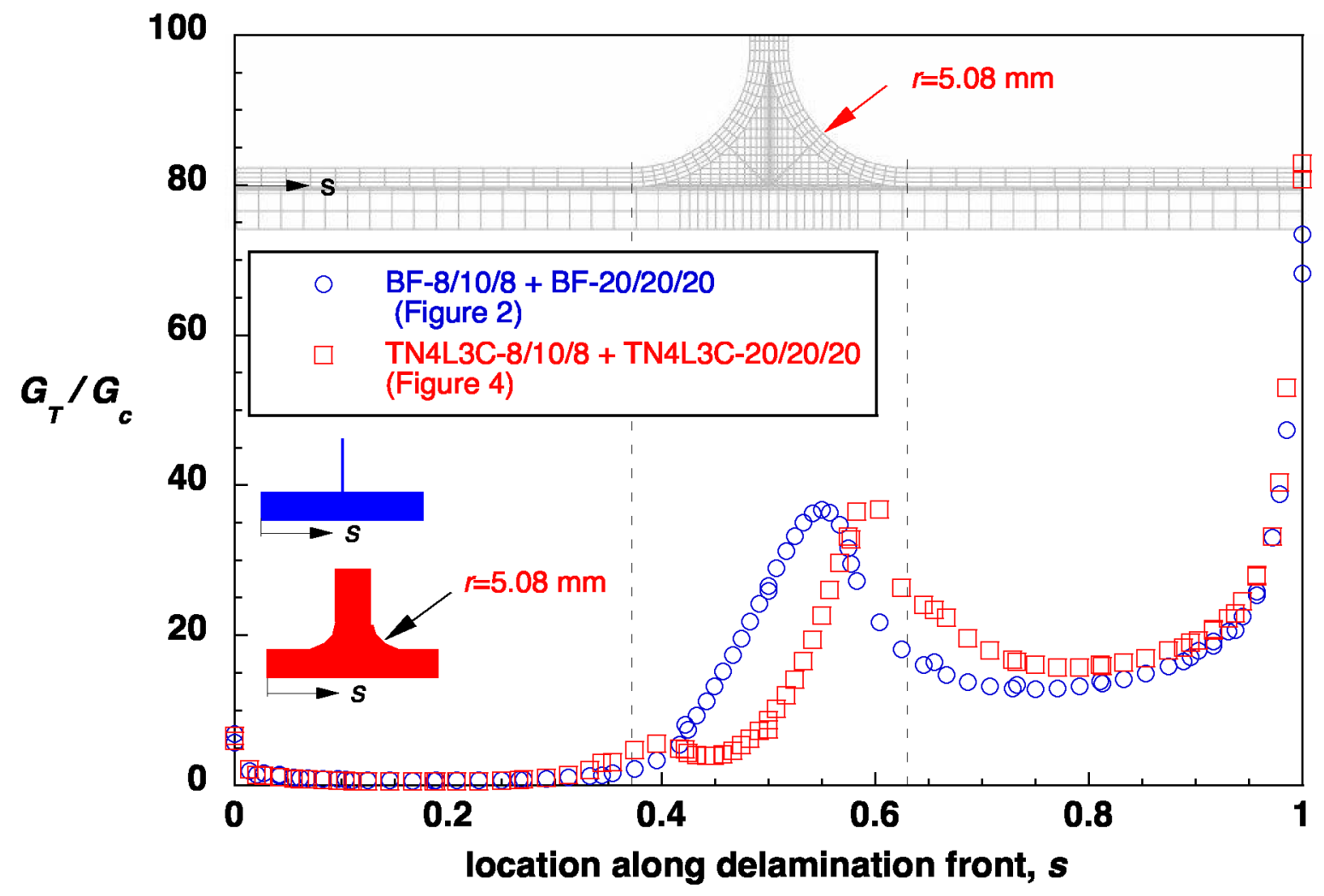

Figure 10. Computed failure index - results for radius $r=5.08 \mathrm{~mm}$ versus reference solution 


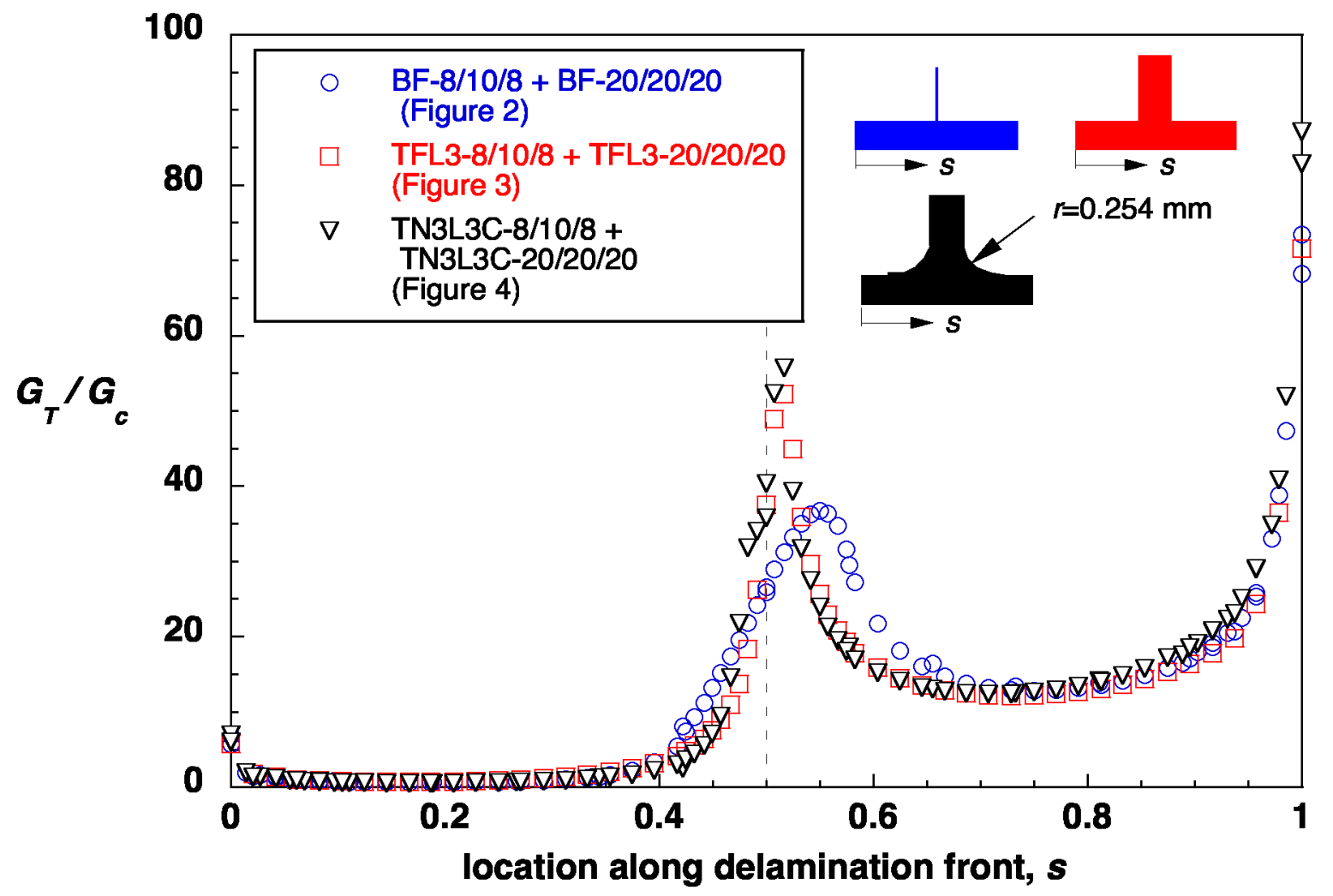

Figure 11. Comparison of results for 3D web, radius $r=0.254 \mathrm{~mm}$ and reference solution

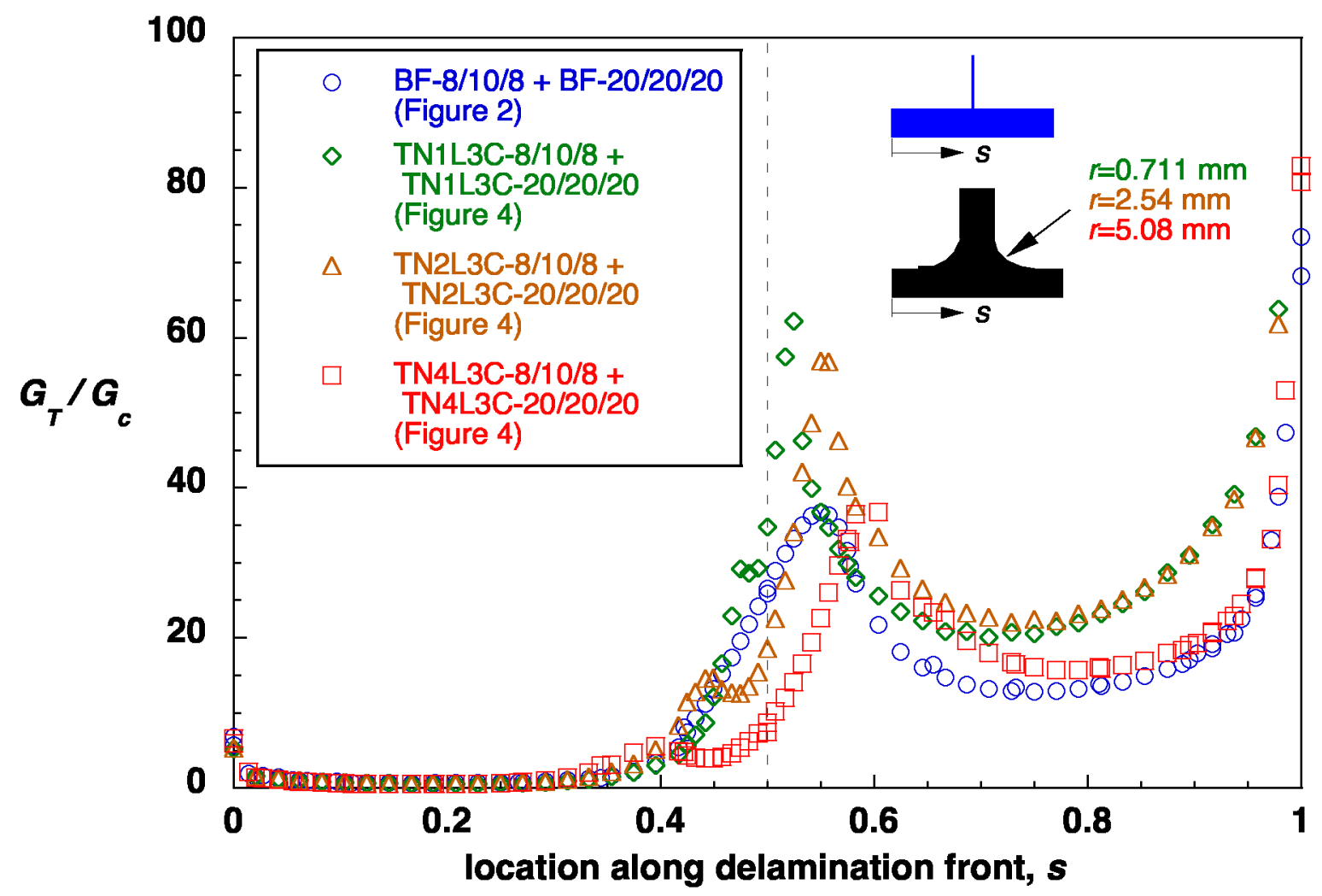

Figure 12. Comparison of results for different radii and reference solution 